\title{
Processing Printed Words in Literary Arabic and Spoken Arabic: An fNIRS Study
}

\author{
Bahaa Madi Tarabya1, ${ }^{1 *}$, Asaid Khateb ${ }^{1,2}$, Samer Andriaa, \\ ${ }^{1}$ The Unit for the Study of Arabic Language, Edmond J. Safra Brain Research Center for the Study of Learning Disabilities, \\ University of Haifa, Haifa, Israel \\ ${ }^{2}$ Department of Learning Disabilities, Faculty of Education, University of Haifa, Haifa, Israel \\ Email: ^bmadi@campus.haifa.ac.il
}

How to cite this paper: Tarabya, B. M., Khateb, A., \& Andria, S. (2021). Processing Printed Words in Literary Arabic and Spoken Arabic: An fNIRS Study. Open Journal of Modern Linguistics, 11, 461-483. https://doi.org/10.4236/ojml.2021.113035

Received: May 15, 2021

Accepted: June 26, 2021

Published: June 29, 2021

Copyright $\odot 2021$ by author(s) and Scientific Research Publishing Inc. This work is licensed under the Creative Commons Attribution International License (CC BY 4.0). http://creativecommons.org/licenses/by/4.0/

\begin{abstract}
Diglossia refers to a socio-linguistic situation in which two varieties of the same language are used for distinct purposes in everyday life. In Arabic, Spoken Arabic (SA) is the firstly acquired dialect used for oral and informal communication in everyday conversations. Literary Arabic (LA), acquired later in life through formal education, is used for reading and writing and by literate individuals in formal settings such as the media and official speeches. Because of the linguistic distance between the two Arabic varieties, some authors have suggested that SA and LA might cognitively function as first (L1) and second language (L2). Up to now, very few studies using imaging techniques had addressed the question of the neural basis of diglossia in Arabic native speakers. In this study, we sought to test whether or not the visual processing of high (LA-HF), low frequency LA words (LA-LF), and SA-HF words induce detectable differences in the brain responses collected by functional Near-Infra Red Spectroscopy (fNIRS). For this aim, a semantic categorization task, previously assessed in fMRI studies. Based on previous observations, it was predicted that LA words, will be processed faster and more accurately than SA ones. Furthermore, it was predicted that a modulation of the responses (by language conditions) will be found in the left frontal areas. At the behavioral level, the analysis of RTs revealed an effect of language variety in individual response variance and accuracy showed a clear advantage for LA-HF words over LA-LF and SA-HF ones. The analysis of oxygenation level revealed a significant response modulation in frontal and posterior areas by language variety. These results are discussed in the context of diglossia and the advantages/limitations of this new imaging methodology and its use to assess language processing in the brain.
\end{abstract}

\section{Keywords}

Diglossia, Visual Word Processing, Semantic Categorization Task, Spoken 
Arabic, Literary Arabic, Word Frequency

\section{Introduction}

The Arabic language is thought to present several unique particularities that affect children's literacy development, reading and writing skills (Ayari, 1996; Levin, Saiegh-Haddad et al., 2008; Saiegh-Haddad \& Geva, 2008) (see also Saiegh-Haddad, 2020). These include, first, a visually complex $a b j a d^{d}$ writing system that is written from right to left in a cursive script and comprises 28 consonant letters, of which three serve also as long vowels (Saiegh-Haddad \& Joshi, 2014). Secondly, Arabic has also a complex and dense morphological (and morpho-syntactic) system in which words are produced mainly on the basis of non-linear combination of roots representing the meaning of the word, and of patterns representing their lexical and syntax categories (see for details Taha \& Saiegh-Haddad, 2017). Most importantly, Arabic is widely regarded as a classic example of diglossia (Ferguson, 1959), a socio-linguistic situation in which two varieties of the same language are used for distinct purposes in everyday life. Spoken Arabic (SA) is the dialect firstly acquired by native speakers of Arabic, is the mother tongue of all native speakers of Arabic all over the world and is used for oral and informal communication in everyday conversations. Literary Arabic (LA, also referred to as Modern Standard Arabic, MSA (Saiegh-Haddad, 2004), referred to also as StA for "Standard Arabic" (Schiff \& Saiegh-Haddad, 2018) is a recent variety of the classical Arabic, and used by literate individuals in formal settings such as in official media, for speeches and religious sermons. LA is learned through formal education and is the medium for written language-reading and writing (Zughoul, 1980; Ibrahim, Eviatar et al., 2002; Saiegh-Haddad, 2005). While LA is the same language throughout the entire Arabic-speaking world, the spoken vernacular Arabic forms vary considerably between the world's different geographical regions (Saiegh-Haddad, 2003; Saiegh-Haddad, 2004).

Because of these various unique characteristics of the Arabic language, authors consider that reading and writing acquisition in Arabic is a very challenging task (Saiegh-Haddad, 2003, 2005; Ibrahim, 2009). The combination of these characteristics is thus thought to explain the poor achievements of students in all Arabic-speaking countries in international reading tests (Kashti, 2013). In this respect, the scientific literature is very also rich in studies that investigated the influence of the particular characteristics of the orthographic system on word recognition (Ibrahim, Eviatar et al., 2002; Abdelhadi, Ibrahim et al., 2011; Taha, Ibrahim et al., 2013; Asadi, Khateb et al., 2017) and of the diglossia on reading performance and on linguistic skills more generally (Saiegh-Haddad, 2004; ${ }^{1} \mathrm{An}$ abjad is a type of writing system where each symbol always/or usually stands for a consonant, leaving the reader to supply the appropriate vowels. This system is suited to the Arabic root and word pattern morphological structure, where the most basic semantic meaning is carried by the consonantal root and where vowel information may be recovered from the vocalic word pattern (Saiegh-Haddad \& Joshi, 2014). 
Saiegh-Haddad, Levin et al., 2011). For instance, it had been shown that skilled native Arabic speakers are slower in reading Arabic (words and texts) than reading Hebrew and English (Abu-Rabia, 2001; Ibrahim \& Eviatar 2012; Eviatar, Ibrahim et al., 2019).

Regarding the diglossic issue more specifically, psycholinguistic studies have shown that the linguistic distance between SA and LA impacts a variety of linguistic processing skills in LA (For a review see, Saiegh-Haddad, 2018). SA and LA present differences at the phonological, semantic, morphological and syntactic levels (Abu-Rabia, 2000; Saiegh-Haddad, 2003; Saiegh-Haddad, 2020). To give some examples specifically related to the purpose of this study, at the lexical semantic level, although SA and LA share many words in common (despite certain phonological nuances), SA and LA also have different specific words for the same referents. To illustrate this fact, Saiegh-Haddad and Spolsky (Saiegh-Haddad \& Spolsky, 2014) analyzed a lexical corpus collected from five-year-old children's oral language and found that $40 \%$ of the words consist of nonstandard words (non-MSA) that have no conventional written form, another $40 \%$ consisting of SA-LA cognates (with varying phonological nuances) and only $20 \%$ of the words had identical forms in the SA and LA varieties. The phonological systems of LA and SA thus are quite different to the extent that some LA phonemes are even absent in certain SA dialects. Accordingly, the phonological distance between SA and LA words had been proposed to underlie the difficulties in reading acquisition among children (Saiegh-Haddad, 2007). For example, previous research had suggested that the children's recognition of LA phonemes is poorer than that of SA ones (Saiegh-Haddad, Levin et al., 2011), attesting of the difficulty to construct phonological representations for LA words, to which children are generally exposed for the first time ${ }^{2}$ at the moment of their entry to school (see also Saiegh-Haddad, 2003; Saiegh-Haddad, 2007; Saiegh-Haddad \& Schiff, 2016). Supporting the claim that diglossia might be at the origin of difficulties in reading acquisition among Arabic children, previous studies (Feitelson, Goldstein et al., 1993; Abu-Rabia, 2000) have also suggested that early exposure to LA might improve children's reading abilities in the early grades.

On the other hand, other research based on classical studies on bilingualism have attempted to assess the extent to which SA and LA might cognitively behave as L1 and L2 in the brain of literate Arabic speakers. Ibrahim and Aharon-Peretz (2005) have proposed on the basis of a series of studies using semantic priming tasks, despite their common origin and the wide use of SA and LA by adults' native Arabic speakers, the two varieties function as first and second language. In these studies using lexical decision in the auditory modality, the authors showed a pattern of language dominance for SA over LA and Hebrew, where the latter two seemed to behave both as second languages (see also Eviatar ${ }^{2}$ Although the formal exposure to LA occurs at the entry of children to school, they are still however exposed to LA through media and TV programs for children and through oral storytelling by parents and educators at home and in kindergartens (see discussion in Saiegh-Haddad \& Spolsky, 2014). 
\& Ibrahim, 2000; Ibrahim, Eviatar et al., 2002; Ibrahim \& Aharon-Peretz, 2005; Ibrahim, 2009). In another line of research, Eviatar \& Ibrahim (2000) have shown that Arabic-speaking children, who have been exposed relatively early to LA, behaved as bilingual children on tests of metalinguistic awareness, and differed from monolinguals. The conclusions raised by these authors in the auditory modality appeared quite reasonable given the history of acquisition and patterns of use of the two varieties of Arabic. In fact, few studies had used the visual modality to compare word recognition and reading in LA and SA. The lack of such experimental studies stems from the fact that $\mathrm{SA}$ is generally considered as an oral language that has no consensually agreed upon written form, hence more studies relied on auditory paradigms. However, in one early study using the visual word presentations, Bentin and Ibrahim (1996), examined written LA and SA words' recognition (with non-words in a lexical decision task) and reading aloud (in a word naming task). The authors reported that LA words were processed more rapidly than SA ones, with the latter functioning as low frequency LA words. Their results suggested that word recognition in SA was more mediated by phonological processes than LA ones. From this latter study in the visual modality and others in the auditory modality, it had recently been suggested that the status of SA and LA in terms of dominance is modality-dependent: SA being the dominant variety in the auditory modality and LA being the dominant one in the visual modality (Nevat, Khateb et al., 2014). Recent data have indeed confirmed that response times (reaction times: RTs) to words in the auditory modality are faster for SA than for LA words while in the visual written modality the responses to LA words are faster and more accurate (see also Khateb \& Ibrahim, 2020).

Although at the behavioral level, the response to the dominance question appears intuitively done, one can ask how these two varieties of Arabic are represented in the brain. The question of brain representation of the two Arabic varieties, relying on such behavioral studies does not give enough answers to understand the neurofunctional bases of the diglossic situation. Indeed, unlike neurocognitive studies in the field of bilingualism that sought to provide answers to the question of the bilinguals' languages representation in the brain, (Keatley, Spinks et al., 1994; Kim, Relkin et al., 1997; Fabbro, 2001; Perani \& Abutalebi, 2005; Hull \& Vaid, 2006; Emmorey, Giezen et al., 2016; Miller, Bayram et al., 2018), the diglossic question has up to now barely been investigated using neurofunctional methods (Khamis-Dakwar \& Froud, 2007; Ahmed, 2012; Nevat, Khateb et al., 2014). Of particular interest to this question is the study Krayem Abu Ahmed (2012) that analyzed event-related potentials (ERP) during an auditory lexical decision task that compared brain responses to SA, LA and Hebrew words. Not only RTs were shown to be faster to SA words (than to LA and Hebrew ones), ERPs displayed early response differences between SA and the two other language conditions, supporting the dominant status of SA variety. In a subsequent study by Andria (Andria, 2016), ERPs were analyzed during a visual lexical deci- 
sion task using LA high frequency (LA-HF), low frequency (LA-LF) and SA high frequency SA-HF words. Together with the fact that RTs showed here that the shortest responses were obtained after LA-HF words, ERP analysis indicated that both at the level of the N170, and the late P6, a higher response amplitude was observed after LA-HF in comparison to LA-LF and SA-HF, with no differences between the two other conditions. These findings provided also support to the assumption of LA holding the status of the dominant variety in the visual modality. In line with these findings, the study by Nevat, Khateb and Prior (2014) analyzed fMRI responses during the processing of LA, SA and Hebrew written words in a semantic categorization task. Here again, the behavioral measures showed that decisions for SA were slower and less accurate than for words for LA ones. More importantly, the functional responses in the left inferior frontal, precentral, parietal and occipito-temporal regions showed stronger activation to SA than LA, a pattern of difference that mimicked to some extent those reported by L2 vs. L1 comparisons in previous studies (Chee, Hon et al., 2001). The authors interpreted these findings in terms of differences in the exposure (and subjective familiarity) to the written forms of SA vs. LA. Altogether, while providing support to the view that the question of dominance in diglossia is modality-dependent, these previous findings from ERP and fMRI studies call for a combination of behavioral and brain functional measures in order to provide new insights into the question of the status of SA and LA in the brain of native Arabic speakers.

In continuity with this vision, and given the fact that each neuroimaging method might have its characteristics that may present drawbacks and limitations in the study brain activity, the present study sought to employ functional near-infra read spectroscopy (fNIRS) to further investigate the question of diglossia in Arabic. ANIRS is an optical imaging technique that allows the non-invasive measurement of changes in the concentration of oxygenated (oxyHb) and deoxygenated (deoxyHb) hemoglobin (Sela, Izzetoglu et al., 2012). Regional brain activation is known to be accompanied by increases in regional cerebral blood flow and in the regional cerebral oxygen metabolic rate. When the degree of increase in regional cerebral blood flow exceeds the degree of increase in the regional cerebral oxygen metabolic rate (Fox \& Raichle, 1986), the result is a decrease in deoxyHb in venous blood. Hence, under NIRS measurements, an increase in oxyHb and a decrease in deoxyHb are interpreted as indicating activated areas (Hoshi \& Michael, 2005). Of note is the fact that NIRS enables the measurement of $\mathrm{Hb}$ concentration changes in the cortex immediately beneath the probes, but with a relatively poor spatial resolution. During the last two decades, fNIRS has been used in several language studies conducted with infants, children (Horovitz \& Gore, 2004; Minagawa-Kawai, Mori et al., 2008; Gervain, Mehler et al., 2011; Sugiura, Ojima et al., 2011; Jasinska \& Petitto, 2013; Ludyga, Mücke et al., 2019) and adults (for a review see Feitelson, Goldstein et al., 1993; Ferrari \& Quaresima, 2012; Quaresima, Bisconti et al., 2012; Vanderwert \& Nelson, 2014). fNIRS 
has also been used to study neural correlates of linguistic and non-linguistic processing in native and non-native languages (Telkemeyer, Rossi et al., 2009; Arimitsu, Uchida-Ota et al., 2011; Plichta, Gerdes et al., 2011; Jasińska \& Petitto, 2014; Vannasing, Florea et al., 2016).

Relevant to the present purpose, a previous study was conducted on 484 elementary school children (6 - 10 years) who performed word repetition tasks in their native language (L1 Japanese) and a second language (L2-English) while investigating three factors: language (L1/L2), word frequency (high/low), and hemispheric laterality (left/right). The study revealed that the cortical activation pattern associated with language processing in elementary school children involved a bilateral network of regions in the frontal, temporal, and parietal lobes. One of the major finding was, L1 words elicited significantly greater brain activation than L2 words, regardless of semantic knowledge, particularly in the superior/middle temporal and inferior parietal regions while L2 unfamiliar words were processed like non-words auditory stimuli in the brain as indicated by lower activation than that elicited by L1 words in the superior/middle temporal and inferior parietal regions. Moreover, low-frequency words elicited more right-hemispheric activation (particularly in the supramarginal gyrus) and highfrequency words elicited more left-hemispheric activation (Sugiura, Ojima, Matsuba-Kurita, Dan, Tsuzuki, Katura, \& Hagiwara, 2011). In another study, Kahlaoui and her colleagues (2007) examined the hemispheric dynamics during lexical decision task among 10 younger adults (age range 25 - 35) and 10 older adults (age range 65 - 84) participants. The results showed significant hemispheric differences between the word and pseudo-word conditions with increased blood oxygenation patterns observed in pseudo-word conditions across both hemispheres. In another study that investigated the role of the dorsolateral prefrontal cortex (PFC) in semantic processing in bilingual adults, the participants performed a semantic judgment task. Their results suggested that bilinguals had significantly higher activation than the monolinguals in the left dorsolateral prefrontal cortex for correct answers (Oi, Saito et al., 2010). Another study conducted on French adults who were asked to perform a lexical decision task showed increasing tHB when participants started reading and with a return to baseline level once they stopped reading (Safi, Lassonde et al., 2012). In line with these studies, Quaresima, Ferrari, Van der Sluijs (2002) asked participants to translate aloud from their L1 (Dutch) into English L2 and vice versa. The results showed an increase in oxygenated hemoglobin accompanied with delayed and smaller decrease in deoxygenated hemoglobin over Broca's and interior temporal areas. Taken together, these examples suggest that fNIRS method might be a useful tool to investigate reading processes and to understand the differences that might arise in the brain activity between LA and SA words.

The current study sought to investigate differences in fNIRS responses during the processing of LA and SA words. Up to date, no studies have used fNIRS among native Arabic speakers to assess the neural basis of diglossia. For this 
purpose, we collected behavioral and fNIRS data from Arabic speaking adult participants during the performance of a semantic categorization task. Based on previous fMRI results by Nevat et al. (2014) which showed difference between the processing of SA and LA words, this study capitalized on the differences previously found between high-frequency SA words and high-frequency LA words. Hence, we hypothesized that reaction times (RTs) and accuracy will show significant differences between written SA and LA words with LA ones being processed faster and more accurately. Also, we predicted that a modulation of fNIRS responses will be in left frontal areas (inferior frontal gyrus, Broca's area) together with other more posterior areas.

\section{Materials and Methods}

\subsection{Participants}

Thirty native literate Arabic speakers were recruited from the University of Haifa ( 15 men, 15 women, aged $18-30 ; \mathrm{M}=24.3 \mathrm{y}, \mathrm{SD}=4.25 \mathrm{y}$ ). All participants were right-handed (mean laterality index $=0.92, \mathrm{SD}=0.08$, according to the Edinburg inventory, Oldfield 1971) and had Arabic as their mother language. All had been exposed to formal instruction of LA since first grade. All participants were healthy with no history of neurological/psychiatric diseases or learning disabilities and had normal or corrected to normal vision. They were all asked to sign a written consent form prior to their participation in the study and were all paid for their participation. The study protocol was approved by the ethics committee of the Faculty of Education at the University of Haifa.

\subsection{Stimuli}

All participants performed a semantic categorization task (based on Seghier, Lazeyras et al., 2004; Nevat, Khateb et al., 2014) in a block design paradigm that alternated between blocks of word pairs (hereafter Activation condition) and blocks of symbol string pairs (hereafter Control condition). The word stimulus list included 72 pairs of SA high frequency words (SA-HF), 72 pairs of LA high frequency words (LA-HF) and 72 pairs of LA low frequency words (LA-LF). All words were concrete imaginable nouns. The word pairs from each sub-list were presented in blocks of 12 pairs each, providing thus for all word pairs a total of 18 distinct blocks ( 6 for SA-HF, 6 for LA-HF and 6 for LA-LF). The words in each pair were either categorically related (i.e., two words were exemplars of the same semantic category, $2 / 3$ of the pairs) or semantically unrelated (i.e., the two words belonged to two different semantic categories, $1 / 3$ of the pairs). The participants were asked to respond after the presentation of each pairs if the words are related or not (see Table 1 for examples). The selection of the words was based on a questionnaire which was presented filled by 18 young native Arabic speaking participants (who did not participate in the experiment, mean age $\mathrm{M}=$ $24.25, \mathrm{SD}=4.95)$ who were asked to rate the frequency/familiarity of 200 words in each language variety on a scale from 1 to 5 ( 1 least frequent/familiar, 5 most 
Table 1. Examples of the different experimental conditions. The whole data was composed of 216 word pairs distributed equally in three conditions.

\begin{tabular}{|c|c|c|c|}
\hline & $L A H F$ & $L A L F$ & $S A H F$ \\
\hline \multirow[t]{2}{*}{ Related words } & $\begin{array}{c}\text { أمطار - غيوم (e.g. rain-clouds) } \\
\text { (أ) }\end{array}$ & $\begin{array}{c}\text { ماس - زمرد - ماس (e.g. diamonds-emerald) }\end{array}$ & $\begin{array}{c}\text { جزدان - شنطة } \\
\text { (e.g. wallet-bag) }\end{array}$ \\
\hline & $\begin{array}{c}\text { طاوله - كرسي } \\
\text { (e.g. table-chair) }\end{array}$ & $\begin{array}{c}\text { شراع- مرساة } \\
\text { (e.g. sail-anchor) }\end{array}$ & $\begin{array}{c}\text { سيخ-زلفه (e.g. knife-spoon) } \\
\text { (e. }\end{array}$ \\
\hline \multirow[t]{2}{*}{ Unrelated words } & $\begin{array}{c}\text { قلم - صحن (e.g. pen-plate/dish) } \\
\text { (ق) }\end{array}$ & $\begin{array}{c}\text { درّاجه - حساء } \\
\text { (e.g. bicycle-soup) }\end{array}$ & $\begin{array}{c}\text { كريك - ترين } \\
\text { (e.g. shovel - train) }\end{array}$ \\
\hline & $\begin{array}{c}\text { قنديل - عصفور } \\
\text { (e.g. lamp-bird) }\end{array}$ & $\begin{array}{c}\text { (e.g. vملدلا - مُربى } \\
\text { (elume-butter) }\end{array}$ & $\begin{array}{c}\text { خرخشية - سكملا } \\
\text { (e.g. rattle-stool) }\end{array}$ \\
\hline
\end{tabular}

frequent/familiar). In the second step, the most frequent 180 words were arranged to form pairs with LA-HF words $(M=4.896, S D=0.28)$, LA-LF words $(M=1.567, S D=0.292)$ and with SA-HF words $(M=4.894, S D=0.145)$. Another questionnaire was presented to another group of native Arabic speakers who were requested to rate the semantic relationship within each of the pairs from 1 to 5 . The average relatedness in each language condition was above 4 for the related words pairs in LA-HF $(M=4.98, S D=0.08)$, in LA-LF $(M=4.97, S D$ $=0.20)$ and in SA-HF $(M=4.99, S D=0.14$, see Table 1 for examples).

The Control condition used pairs of Greek letter strings (unfamiliar visual stimuli in this population) that were either visually identical or not, i.e., the same string was presented twice or one string differed from the other by one or more character. The participants had to decide whether the two strings in each pair are visually the same or not. Each experimental run contained 6 blocks of the activation condition (word pairs) and 6 blocks of the control conditions (string pairs), yielding thus a total run duration of 4.8 minutes. All participants underwent three experimental runs (for LA-HF, LA-LF and SA-HF), the order of which was balanced over participants. Finally, in order to ensure that the tasks were correctly understood, all participants were provided with detailed instructions before starting the recording (see Figure 1 for a schematic presentation of the bloc design).

\subsection{Procedure}

The experiment was carried out in a sound isolated room at the laboratory of the Edmond J. Safra Brain Research Center for the Study of Learning Disabilities (University of Haifa). Participants underwent one session of fNIRS recording. Each trial (both in the activation and the control blocks) was of $\sim 2$ seconds duration and started with a $500 \mathrm{~ms}$ fixation cross, then followed by the stimulus pair which appeared on the screen for $600 \mathrm{~ms}$. An additional blank screen appeared for $890 \mathrm{~ms}$ to allow for the participants' response (yielding thus a total of $1.5 \mathrm{~s}$ for the response from stimulus onset, see Figure 2). In the activation blocs, the stimulus consisted of two words presented one below the other. In the control 
A Bloc design for the semantic categorization task task

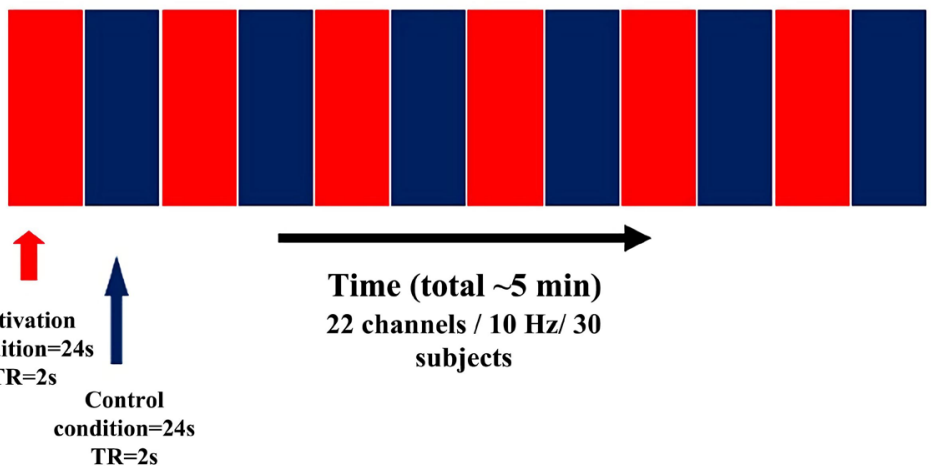

B

Semantic categorization task
Activation condition
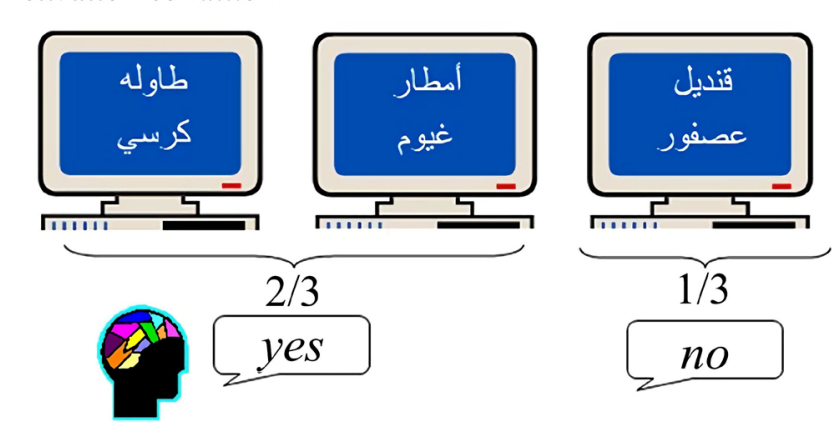

\section{Control condition}
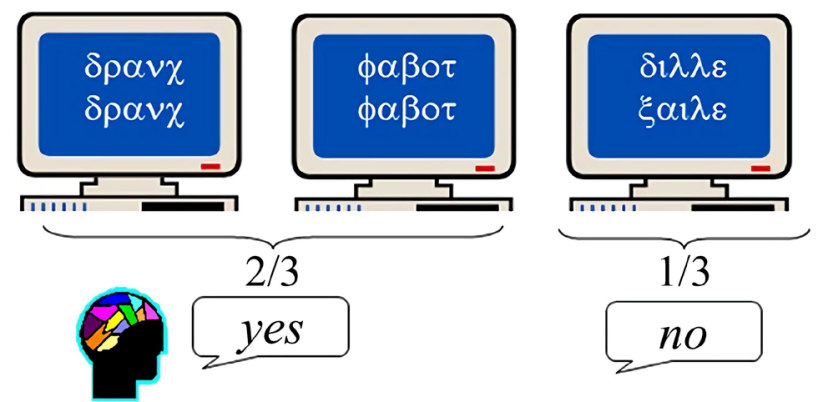

Figure 1. (A) Schematic presentation of the bloc design (for LA-HF, LA-LF and SA-HF) used for the fNIRS experiment. For other methodological details see text. TR refers to the duration of one trial such that each bloc (24 s) contained 12 stimulus pairs. (B) Schematic presentation of the activation and control conditions in the Semantic categorization task. In both the activation and control blocs, the "yes" trials represented 2/3 and the "no" trials represented $1 / 3$.

condition blocs, the stimulus consisted of two Greek letter strings presented one below the other (see Figure 1). The participants were instructed to give their responses (semantic judgment for words and visual judgment for letter strings) as quickly and accurately as possible using one of two response buttons by using their right-hand middle and index fingers. During fNIRS measurement, participants were seated at about $120 \mathrm{~cm}$ from the screen and instructed to look at a fixation point. In order to minimize head motion, subjects were asked to avoid movements as much as possible during the tasks. 
A

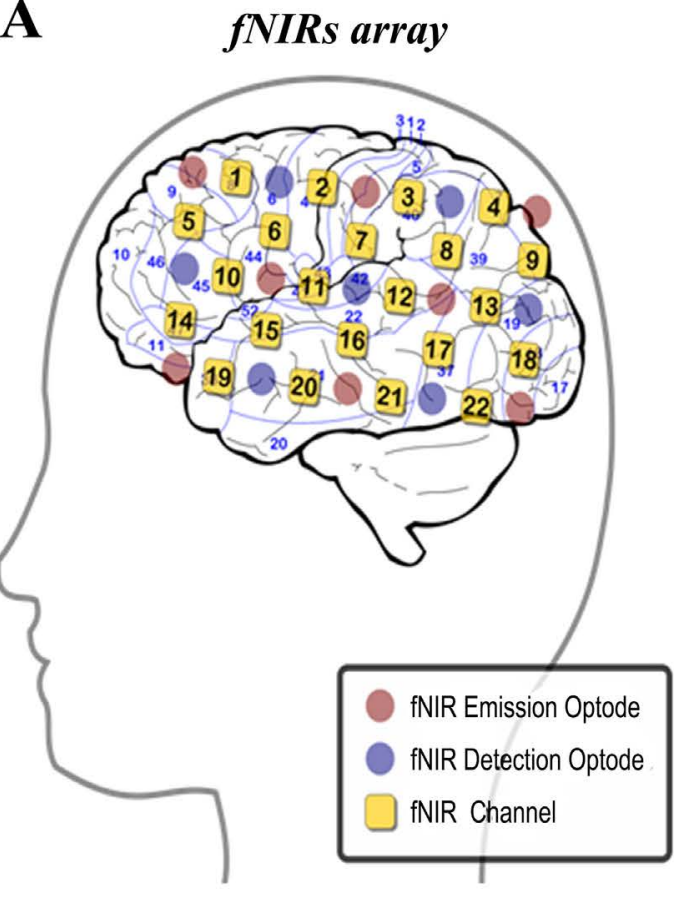

C Activation vs. Control in LALF
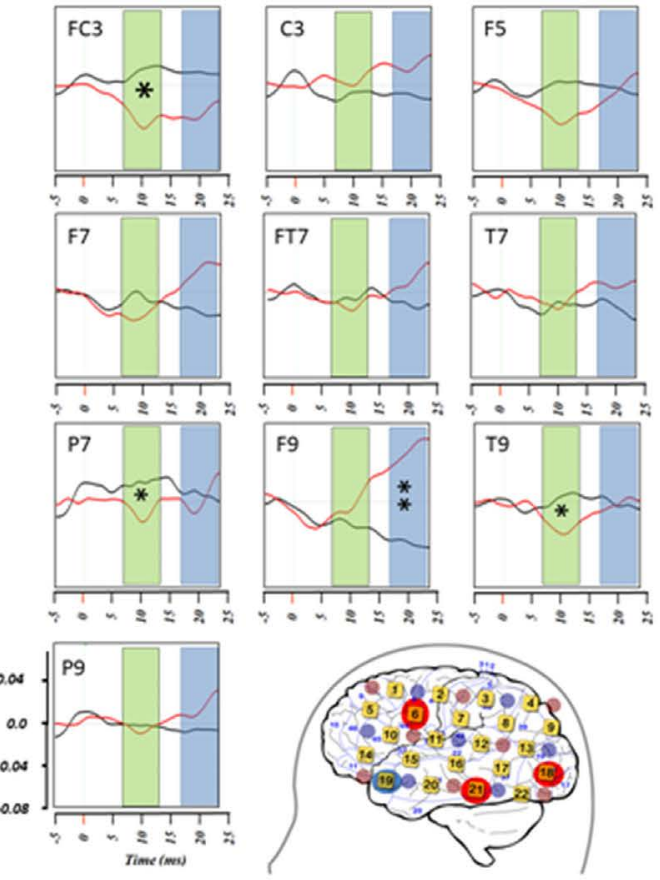

B Activation vs. Control in LAHF
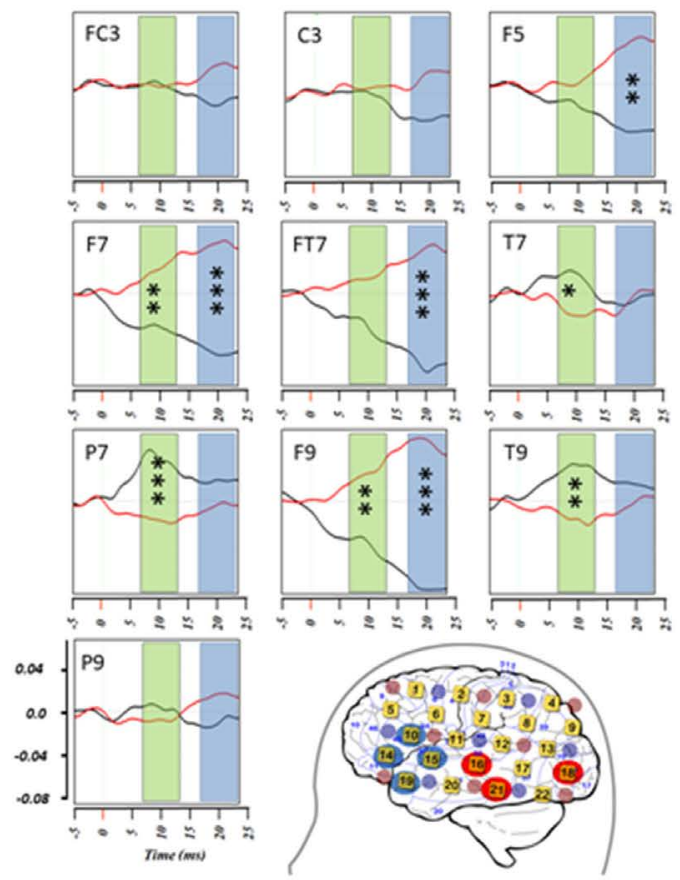

D Activation vs. Control in SAHF
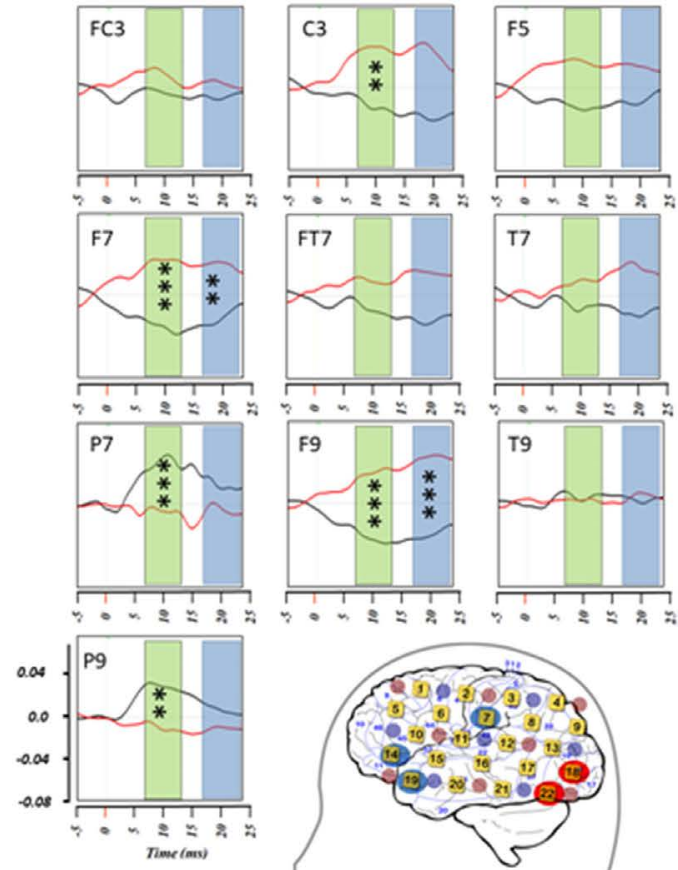

Figure 2. (A) Schema of fNIRS probe array. (B-D) Illustration of the 10 channels in which the major differences between the two conditions (black traces for activation and read traces for control condition) were seen in the grand data and confirmed by statistical analysis in LA-HF (B), LA-LF (C) and SA-HF (D). The first time window analyzed was between $7-13 \mathrm{~s}$ (green) and the second time window between $17-13 \mathrm{~s}$ (blue). Significant differences are indicated by ${ }^{*}$ for $p<0.05,{ }^{* *}$ for $p<0.01$ and ${ }^{* *}$ for $p<0.001$. Insets in B-D show the location of significant differences (in red for Red $\mathrm{p}$ values refer to Activation $>$ Control, in blue Control > Activation). 


\subsection{Data Collection and Analysis}

The data was collected using a 22 channel spectrometer fNIRS device (Optical Topography System ETG-4000-Hitachi Medical Corporation, https://www.hitachi-medical.com.sg/solutions/etg-4100). A computer was placed in the adjacent room to present the task stimuli using E-Prime 2.0 software (Psychology Software Tools, Inc.

http://www.pstnet.com, PA, USA) and to collect participants' responses (accuracy) and reaction times (RTs).

Cerebral oxygenation changes were sampled by fNIRS device. The system is a continuous wave device which measures changes in attenuation at 2 wavelengths: $695 \mathrm{~nm}, \pm 20 \mathrm{~nm}$ (sensitive to HbR concentration changes) and $830 \mathrm{~nm}$ $\pm 20 \mathrm{~nm}$ (sensitive to $\mathrm{HbO}$ concentration changes), hence allows for the differentiation of two dynamic absorbers (oxy-Hb and deoxy-Hb). The fNIRS data was recorded at $10 \mathrm{~Hz}$ and high-pass filtered at $0.5 \mathrm{~Hz}$ to remove physiological noise (especially heart rate). A $3 \times 5$ array of 8 laser diodes and 7 light detectors was applied, resulting in 22 channels placed over the left side of the participant's head (see Schema in Figure 2(A)). Two different helmet sizes were used (57 and $59 \mathrm{~cm}$ ) depending on the head circumference of the participants. The probe array was positioned on the subject's head with the medial detector of the lowest optodes row between FT9-T9 according to the extended 10 - 20 system (Fisch, 1991) as illustrated in Figure 2(A) (here 20 - 21). The name 10 - 20 refers to the fact that electrodes in this system are placed at sites $10 \%$ and $20 \%$ from four anatomical landmarks: in the front, the nasion is used, in the rear of the head, the inion, and the midpoint of the distance between the two ears of the subject. Hair around sources and detectors was parted to avoid interference with light emission and detection. All sources and detectors were placed over the left hemisphere, on cerebral regions classically involved in reading processes: Broca's (around F3, FC3, F5, and FC5: here channels 5, 6, 10, 11), Wernicke's (around P5, CP5-CP7: channels 12, 13, 17) and occipito-temporal areas (visual word form area: T9-P9 here channels 21 -22). The source-detector distance was $3 \mathrm{~cm}$ one from each other.

Behavioral Data analysis, the mean reaction time (RT) for correct responses and accuracy (\%) were computed separately for each condition and participant. Statistical analysis were afterwards performed on these measures using $3 \times 2$ repeated measures analyses of variances (ANOVA) with language condition (LA-HF, LA-LF and SA-HF) and condition (activation vs. control) as a within subject factor.

ANIRS data Analysis. since $\mathrm{HbO}$ signal is a more sensitive indicator of changes in blood flow (Strangman, Culver et al., 2002), only oxyhemoglobin [oxy-Hb] data were processed off-line using Matlab software. The data were filtered to remove respiration, cardiac variations and high-frequency noise (mainly due to head motion and reduction of the grip of the optic fibers on the hairy areas). A low-pass filter with a cut off frequency of $0.14 \mathrm{~Hz}$ was used. In a second step, 
data were converted to measurements of oxy- $\mathrm{Hb}$, arranged into epochs for the different blocks (from $-5 \mathrm{~s}$ pre-block to $23.5 \mathrm{~s}$ post block). An average time course was then computed for each participant and each channel in each condition (activation and control conditions). Individual data were then averaged to generate grand means for visualization and illustration purposes. Based on the visual inspection of the time course of the grand average signals, two time windows appeared to display signal differences between activation and control conditions. The mean signal for each channel and condition in each participant was computed in the period between $7-13 \mathrm{~s}$ after the beginning of each block for the first time window, and between 17 - $23 \mathrm{~s}$ for the second time window (see Figure 2 hereafter). A repeated measure analysis of variance (ANOVA) was then conducted on the individual mean [oxy-Hb] signal in each of the two time windows with language variety, condition and channels as within-subject factors.

\section{Results}

\subsection{Behavioral Results}

The means and standard deviation of the behavioral measures (accuracy and RTs) for the activation and control blocks in the three language conditions are presented in Table 2. The accuracy was computed as the percentage of correct responses (for yes and no together, 72 trials) in the activation and control blocks. The $3 \times 2$ repeated measures analyses of variance (ANOVA) with language variety (LA-HF, LA-LF and SA-HF) and condition (activation vs. control) as a within subject factor showed a significant main effect for language variety ( $F(2$, $\left.58)=5.552, p<0.01, \eta^{2}=0.160\right)$ and for condition $(\mathrm{F}(1,29)=204.153, p<$ $\left.0.001, \eta^{2}=0.876\right)$. The language effect was due to higher accuracy in LA-HF (M $=78 \%)$ than for LA-LF $(\mathrm{M}=76 \%)$ and SA-HF $(\mathrm{M}=74 \%)$. The condition effect was due to the fact that accuracy was higher in the control $(\mathrm{M}=86 \%)$ than in the activation condition $(\mathrm{M}=66 \%)$. There was also a highly significant interaction between the two factors $\left(F(2,58)=10.924, p<0.001, \eta^{2}=0.274\right)$. This interaction was due to the fact that condition effect, although significant in all language varieties, was smaller in LA-HF (see Table 2 for details).

The ANOVA conducted on the participants RTs showed no significant main

Table 2. Accuracy and RTs ( \pm Standard Deviation) on semantic categorization and control tasks by language.

\begin{tabular}{ccc}
\hline & Mean Accuracy in \% & Mean $R$ T in ms (SD) \\
\hline LA-HF activation & $71.00(24)$ & $682.73(167.99)$ \\
LA-LF activation & $64.30(20)$ & $695.88(235.83)$ \\
SA-HF activation & $62.73(13)$ & $710.17(230.01)$ \\
LA-HF control & $85.92(19)$ & $529.17(95.14)$ \\
LA-LF control & $88.20(17)$ & $521.32(92.45)$ \\
SA-HF control & $85.70(21)$ & $534.62(107.92)$ \\
\hline
\end{tabular}


effect of language variety (LA-HF, LA-LF and SA-HF; F $(2,58)=1.185, p=$ $0.313, \eta^{2}=0.039$ ). Less of our interest, a highly significant main effect was found for condition $\left(F(1,29)=51.786, p<0.001, \eta^{2}=0.641\right)$ due to shorter times in the control blocks $(M=528 \mathrm{~ms})$ than in the activation blocks $(M=696 \mathrm{~ms})$. In order to further assess the difference in terms of response speed in the three language varieties, the individual standard deviation of the participants' responses in each language condition was subjected to a one-way ANOVA. This analysis showed a significant effect of language variety $(\mathrm{F}(2,58)=4.75, p=$ $\left.0.012, \eta^{2}=0.141\right)$ due to the fact that the larger variance was found in SA-HF (M $=242 \mathrm{~ms})$ and lowest in LA-HF $(\mathrm{M}=186 \mathrm{~ms})$, with LA-LF in between $(\mathrm{M}=208$ $\mathrm{ms}$ ) and LA.

\section{2. fNIRS Results}

Figure 2 illustrates the superposition of the grand-average (across subjects) oxygenation for the activation (black traces) and control (red traces) conditions in each language variety (panels B-D) on a subset of fNIRS channels that best exhibited response differences between conditions. The traces show the time course of the response from $5 \mathrm{~s}$ before the onset of the blocks to 23.5. The transparent rectangular green and blue boxes define the two time windows of interest. Statistical analysis was then conducted on the mean signal of individual responses, separately for each time period.

Analysis for the time window 7 - $13 \mathrm{~s}$. The first 3-way ANOVA was conducted on the individual oxygenation mean signal in the first time window using language variety (LA-HF, LA-LF and SA-HF), condition (activation vs control) and channel as within-subject factors This analysis showed a highly two-way interaction between condition and channels $\left(\mathrm{F}(21,609)=3.907, p<0.001, \eta^{2}=0.119\right)$. There was also a small but still significant three-way interaction between the three analysis factors $\left(\mathrm{F}(42,1218)=1.505, p=0.021, \eta^{2}=0.049\right)$. In order to better understand these interactions, separate ANOVAs were conducted for each language variety with condition (activation vs. control) and channel (22) as within-subject factors.

In LA-HF, there was a highly significant interaction between the factors condition and channel $\left(F(21,609)=2.488, p<0.001, \eta^{2}=0.079\right)$. Post-hoc Fisher's LSD test showed that this effect was due to the fact that five channels showed a difference between conditions (activation vs. control: see details in Table 3), with three temporal and parietal channels showing higher oxygenation in activation condition and two frontal channels showing higher oxygenation in the control condition (Figure 2(B)).

In LA-LF, although the interaction between condition (activation vs. control) and channels failed to reach significance $\left(\mathrm{F}(21,609)=1.201, p=0.243, \eta^{2}=\right.$ 0.039 ), post-hoc tests revealed here that three channels showed significant differences between conditions (activation vs. control, see Table 3). These included one frontal and two temporo-parietal channels with higher oxygenation in activation than in control (see Figure 2(C)). 
Table 3. Summary of the statistical differences (in the three language conditions in the two time windows). For the 10 channels exhibiting signal difference between the Activation and Control conditions (see Figure 2).

\begin{tabular}{ccccccc}
\hline & \multicolumn{2}{c}{ LA-HF } & \multicolumn{2}{c}{ LA-LF } & \multicolumn{2}{c}{ SAF } \\
& Time & Time & Time & Time & Time & Time \\
& $7-13 \mathrm{~s}$ & $17-23 \mathrm{~s}$ & $7-13 \mathrm{~s}$ & $17-23 \mathrm{~s}$ & $7-13 \mathrm{~s}$ & $17-23 \mathrm{~s}$ \\
\hline (6) FC3 & & & 0.015 & & 0.002 & \\
(7) C3 & & & & 0.0003 \\
(10) F5 & & 0.006 & & 0.000 & \\
(14) F7 & 0.009 & 0.0004 & & & \\
(15) FT7 & & 0.000 & & & \\
(16) T7 & 0.013 & & & & \\
(18) P7 & 0.0004 & & 0.019 & & 0.000 & \\
(19) F9 & 0.007 & 0.000 & & 0.003 & & \\
(21) T9 & 0.003 & & 0.041 & & & \\
(22) P9 & & & & & \\
\hline
\end{tabular}

As for SA-HF, there was a significant interaction between the condition and channels $\left(\mathrm{F}(21,609)=4.755, p<0.001, \eta^{2}=0.141\right)$. Post-hoc test showed that five channels differentiated conditions (see Table 3). Of these, two parietal channels showed higher signal in activation and three frontal channels displayed higher oxygenation in control condition (Figure 2(D)).

Analysis for the time window $17-23 s$. the 3-way ANOVA performed on the individual oxygenation mean signal in this second time window revealed a highly two-way interaction between condition and channels $(\mathrm{F}(21,609)=2.883, p=$ $\left.0.001, \eta^{2}=0.09\right)$. Although the three-way interaction was not significant (F (21, $609)=0.739, p=0.890, \mathrm{~ns}$ ), separate ANOVAs were again conducted for each language variety with condition (activation vs. control) and channel as within-subject factors.

In LA-HF language condition, there was a highly significant interaction between the two factors $\left(F(21,609)=2.542, p<0.001, \eta^{2}=0.081\right)$. Post-hoc Fisher's LSD tests showed that this was due to the fact that four (out of 22) channels showed a higher values during the control condition than in the activation condition (see details in Table 3).

In LA-LF, there was neither significant main effects of condition and channel, nor an interaction between the two factors $(\mathrm{F}(21,609)=0.804, p=0.716$, ns). However, post-hoc LSD tests showed significant difference in one frontal channel due to larger response in the control than in the activation condition (see Table 3).

Regarding SA-HF, the ANOVA showed a significant interaction between the two factors $\left(\mathrm{F}(21,609)=1.586, p<0.05, \eta^{2}=0.052\right)$. Post-hoc tests showed significant differences only in two frontal channels (see Table 3 ) due to higher re- 
sponse in the control relative to the activation condition.

\section{Discussion}

This study aimed to examine whether or not the visual processing of LA words and SA words induce detectable differences in fNIRS responses, while manipulating word frequency in LA among Arabic native speakers. For this proposal, a semantic categorization task was used with LA and SA written words in an fNIRS paradigm. This block-design paradigm had previously been used to map left hemisphere language areas (Seghier et al., 2004) and had recently been used in Arabic to assess fMRI differences between SA and LA (Nevat et al., 2014). Up to now, several studies have investigated the diglossic issue in Arabic, but very few have used brain imaging to characterize the neural basis of diglossia in the brain of Arabic native speakers.

At the behavioral level, the analysis of RTs showed an effect of language variety only in the analysis of the individual response variance but not in the participants' individual averaged RTs. Accuracy showed as expected a higher rate in LA-HF $(\mathrm{M}=78 \%)$ than in LA-LF $(\mathrm{M}=76 \%)$ and SA-HF $(\mathrm{M}=74 \%)$. These differences between LA-HF and SA-HF are in accordance with previous results using the same paradigm (Nevat et al., 2014). The absence of language effect in the RTs measure contrasts with the previous observation by Nevat et al. (2014). Although difference in paradigm does possibly not explain this lack of difference in RTs, still have to emphasize that this study alternated between three Arabic language conditions while in Nevat et al.'s fMRI study Arabic blocs alternated with Hebrew blocks. Also, possibly as a consequence of the particularity of the paradigm used here that for an unknown reason made it more difficult here, the global accuracy obtained in activation conditions appeared slightly lower here in the fNIRS than in the fMRI study.

In terms of fNIRS responses, we took the option in this study to analyze the oxygenation measure which reflects the difference between oxyhemoglobin and deoxyhemoglobin (oxy-Hb-deoxy-Hb) and this was done separately for the activation and the control conditions. The analyses in all language varieties, conducted to assess the differences in terms of activation, were performed in two-time windows on all channels. The option to use two windows aimed at avoiding missing effects because of possible differences in the time course of the responses. Hence, we expected that whenever differences were found in one of the two-time windows, the direction of the effect will be the same as shown for instance in F7 and F9 channels.

In terms of increased activation, our fNIRS analyses (summarized in Table 3 at the end of the results) showed that for instance when comparing the effects obtained for LA-HF and LA-LF, of the three channels showing an increase in oxygenation in LA-HF, there were two (T9 and P7) which showed the same effect in LA-LF, and which are localized postero-anteriorily along the occipito-to inferior temporal areas. The additional channel that in LA-HF showed increased 
oxygenation was T7 (around the middle-to superior-temporal region), while in LA-LF the additional channel was FC3, which is localized at the lateral dorsal frontal cortex. This observation would suggest that while LA-HF involved more middle-to-suepiror temporal areas, LA-LF involved more the lateral dorsal frontal cortex. When considering SA-HF in comparison with LA-HF, the only channel showing increased oxygenation (in both conditions) was P7 which located posteriorily and involved probably only the posterior occipito-temporal region. Along the same location, SA-HF showed an additional significant increase in P9, a little more posteriorily and more ventrally. The location of these channels, which might partly coincide with the location of visual word form area, would suggest that SA-LF showed more activation in this region. A similar finding was interpreted in fMRI results due to the relatively low familiarity of SA word patterns than LA ones, and to the fact that decoding SA necessitated more computation in this region (Nevat et al., 2014).

Taken together, these differences in terms of increased activation would suggest that the fNIRS oxygenation measure was quite sensitive to assess the differences in processing the three varieties of Arabic. Here, fNIRS analysis could show effects that were not visible in RT measures. One should however be careful about such interpretation of the differences found only in an isolated channel. Actually, as long as the placing of the fNIRS recording channels relies on approximate location, small differences between conditions might also be partially due to small variations in the effects where is some instance small effects just failed to reach significance. A more correct/conservative/careful approach would be to use a cluster of channels (that show differences) as a region of interest in order to avoid effects on simply separate channels. A pre-requisite for the use of such analysis approach would be the need to verify that the direction of the effect in these channels is the same (see for instance channels P7, T7 and P9 [corresponding to channels 16, 18, 22] in Figure 2). In the meantime, having effects on single separated channels would be an inherent feature of fNIRS recordings as reported here because of the small number of channels and of the very low spatial resolution (more than $2.5 \mathrm{~cm}$ between two successive channels). Conducting similar studies with more dense channel distribution would definitely allow avoiding such hesitation about the interpretation and in the same time facilitate the interpretation of the differences thanks to the higher spatial resolution. Also, future studies using this technology should also use sensors positioned not only to sample left hemisphere but also right hemisphere activity.

As for channels showing decrease in oxygenation, channel F9 which is located at the anterior superior part of the temporal gyrus was consistent in all conditions. Together with F9, there were three other frontal channels which showed decrease in activation in LA-HF. All these channels together (with F9) form a region of frontal channels with similar pattern of decreased activation (F5, F7, F9 and FT7) that extended antero-posteriorily along the inferior frontal/superior temporal areas). In LA-LF, there was no other than the F9 channel. In SA-HF, 
together with F9 there was an additional decrease in F7 (as in LA-HF) but also in C3 (around the motor areas). As to the functional significance of these effects, one should again highlight the fact that these differences attest of difference in the processing demands for the three language varieties. LA-HF is the condition which showed the highest level of decrease in frontal region while LA-LF showed the lowest level of decrease (with SA-HF in between). If one considers decrease in activation in these frontal areas as an index of a lower activation demands, then it appears reasonable to say that LA-HF was the condition that necessitated these frontal areas the less to perform the task, followed by SA-HF and then by LA-LF. Finally, as for the fact that SA-HF seemed to necessitate less activation in $\mathrm{C} 3$, one might speculate that this is probably due to the fact that SA words demands in terms of motor-articulatory efforts are lower, hence less activation/more deactivation was observed in these motor areas.

As for the question of diglossia, the only study that investigated the neural basis of diglossia using fMRI and visual presentation of SA and LA words was that reported by Nevat et al. (2014). Actually, two other studies using fMRI were conducted to assess brain activity during picture naming in SA and LA (Abou-Ghazaleh, Khateb et al., 2018) and to investigate language control mechanisms during the use of SA and LA (Abou-Ghazaleh, Khateb et al., 2020). As for our purpose, building on previous observations by Nevat et al. (2014), it was predicted that, since LA is the formal written language, it will be processed faster and more accurate than SA (which usually not encountered in the written form). Furthermore, due to the fact that LA is the first acquired written form and frequently used by Arabic native speakers it would show faster and accurate responses than LA-LF which is not used daily. In accordance with the behavioral hypotheses, it was expected that responses in left frontal areas (inferior frontal gyrus, Broca's area) will be modulated by the language conditions, with LA-HF words inducing the smallest responses and SA-HF and LA-LF showing no or little differences. The behavioral results, while contrasting with other suggesting that SA and LA function cognitively L1 and L2 (Ibrahim \& Eviatar, 2009), are in accordance this Nevat et al. (2014) and Bentin \& Ibrahim (1996) showing an advantage for LA in the visual modality. The results observed in terms of decrease in activation seem to suggest that responses in left frontal areas (inferior frontal gyrus, Broca's area) are indeed modulated by the language conditions, with words of the most dominant LA-HF inducing the smallest responses.

The neurocognitive outcomes of the present study indicate, as in previous studies (Safi et al., 2012), that fNIRS technology might be useful tool to investigate reading processes and understanding the differences that might be reflected in the brain activity. As expected, high activation was observed in the left hemisphere, in regions classically involved in reading processes. Consistent with the behavioral measures, brain oxygenation signals during word condition (activation) showed higher values in the language and reading areas compared to symbol condition (control). As for activation in Broca's area, although no direct 
comparison was made between the different language conditions, the pattern of responses (e.g., more deactivation in LA-HF) observed here seems to be in accordance with previous studies' results. In an fMRI study by Joubert et al. (2004), participants were asked to silently read, high-frequency, and low-frequency words together with nonwords. They authors showed that nonwords and low-frequency relative to high-frequency words, elicited a significantly higher activation in bilateral inferior frontal gyrus.

The activation observed in occipito-temporal areas (visual word form area) indicates higher oxygen concentrations in activation than in control. This can be explained by the fact that word recognition shows higher activation than visual recognition (symbols) (Dehaene \& Cohen, 2011). The review of Mechelli Andrea, Gorno-Tempini, and Price (2003) of nine studies with a comparison of words and pseudowords listed six studies with higher activation for pseudowords than words in areas corresponding to or near to the visual word form area. However, two recent studies used lexical decision instead of reading found the opposite, that is, higher activation for words than pseudowords (Kronbichler et al., 2004; Binder et al., 2003; Fiebach et al., 2002).

To summarize, the behavioral and functional results suggested the presence of response differences between the processing of LA-HF, LA-LF and SA-HF, although no direct comparison was made here for three language conditions. The current study showed that some areas's activation/deactivation (word form area and Broca's area) were modulated by language condition. In continuity with previous investigations, the results of this study (behavioral measures and deactivation in the frontal areas) suggested that the status of SA and LA is modality-dependent, with LA appearing as the dominant variety in the visual modality. This is the first fNIRS study to investigate the diglossic issue. Future studies should probably use other types of analysis in order to better assess the neurofunctional differences between conditions. Also, the use of other systems with more recording channels should definitely improve the spatial resolution. A better control on the stimulus list or the experiment timing parameters should also allow understanding why in this, compared to previous experiments, there were no RTs differences.

\section{Conflicts of Interest}

The authors declare no conflicts of interest regarding the publication of this paper.

\section{References}

Abdelhadi, S. et al. (2011). Perceptual Load in the Reading of Arabic: Effects of Orthographic Visual Complexity on Detection. Writing Systems Research, 3, 117-127. https://doi.org/10.1093/wsr/wsr014

Abou-Ghazaleh, A. et al. (2018). Lexical Competition between Spoken and Literary Arabic: A New Look into the Neural Basis of Diglossia Using fMRI. Neuroscience, 393, 83-96. https://doi.org/10.1016/j.neuroscience.2018.09.045 
Abou-Ghazaleh, A. et al. (2020). Language Control in Diglossic and Bilingual Contexts: An Event-Related fMRI Study Using Picture Naming Tasks. Brain Topography, 33, 60-74. https://doi.org/10.1007/s10548-019-00735-7

Abu-Rabia, S. (2000). Effects of Exposure to Literary Arabic on Reading Comprehension in a Diglossic Situation. Reading and Writing, 13, 147-157. https://doi.org/10.1023/A:1008133701024

Abu-Rabia, S. (2001). The Role of Vowels in Reading Semitic Scripts: Data from Arabic and Hebrew. Reading and Writing, 14, 39-59. https://doi.org/10.1023/A:1008147606320

Ahmed, M. K.-A. (2012). Diglossia in Auditory Lexical Decision: An Event-Related Potential Study. Haifa: University of Haifa, Faculty of Education, Department of Learning Disabilities.

Andria, S. (2016). Diglossia in Arabic: Event-Related Potentials during a Visual Lexical Decision Task. Haifa: University of Haifa, Faculty of Education, Department of Learning Disabilities.

Arimitsu, T. et al. (2011). Functional Hemispheric Specialization in Processing Phonemic and Prosodic Auditory Changes in Neonates. Frontiers in Psychology, 2, 202. https://doi.org/10.3389/fpsyg.2011.00202

Asadi, I. A. et al. (2017). How Simple Is Reading in Arabic? A Cross-Sectional Investigation of Reading Comprehension from First to Sixth Grade. Journal of Research in Reading, 40, S1-S22. https://doi.org/10.1111/1467-9817.12093

Ayari, S. (1996). Diglossia and Illiteracy in the Arab World. Language, Culture and Curriculum, 9, 243-253. https://doi.org/10.1080/07908319609525233

Bentin, S., \& Ibrahim, R. (1996). New Evidence for Phonological Processing during Visual Word Recognition: The Case of Arabic. Journal of Experimental Psychology: Learning, Memory, and Cognition, 22, 309. https://doi.org/10.1037/0278-7393.22.2.309

Binder, J. R. et al. (2003). Neural Correlates of Lexical Access during Visual Word Recognition. Journal of Cognitive Neuroscience, 15, 372-393. https://doi.org/10.1162/089892903321593108

Chee, M. W. et al. (2001). Relative Language Proficiency Modulates BOLD Signal Change When Bilinguals Perform Semantic Judgments. Neuroimage, 13, 1155-1163. https://doi.org/10.1006/nimg.2001.0781

Dehaene, S., \& Cohen, L. (2011). The Unique Role of the Visual Word Form Area in Reading. Trends in Cognitive Sciences, 15, 254-262. https://doi.org/10.1016/j.tics.2011.04.003

Emmorey, K. et al. (2016). Psycholinguistic, Cognitive, and Neural Implications of Bimodal Bilingualism. Bilingualism: Language and Cognition, 19, 223-242. https://doi.org/10.1017/S1366728915000085

Eviatar, Z. et al. (2019). Speed of Reading Texts in Arabic and Hebrew. Reading and Writing, 32, 537-559. https://doi.org/10.1007/s11145-018-9877-y

Eviatar, Z., \& Ibrahim, R. (2000). Bilingual Is as Bilingual Does: Metalinguistic Abilities of Arabic-Speaking Children. Applied Psycholinguistics, 21, 451-471. https://doi.org/10.1017/S0142716400004021

Fabbro, F. (2001). The Bilingual Brain: Cerebral Representation of Languages. Brain and Language, 79, 211-222. https://doi.org/10.1006/brln.2001.2481

Feitelson, D. et al. (1993). Effects of Listening to Story Reading on Aspects of Literacy Acquisition in a Diglossic Situation. Reading Research Quarterly, 28, 71-79. https://doi.org/10.2307/747817 
Ferguson, C. A. (1959). Diglossia. Word, 15, 325-340. https://doi.org/10.1080/00437956.1959.11659702

Ferrari, M., \& Quaresima, V. (2012). A Brief Review on the History of Human Functional Near-Infrared Spectroscopy (fNIRS) Development and Fields of Application. Neuroimage, 63, 921-935. https://doi.org/10.1016/j.neuroimage.2012.03.049

Fiebach, C. J. et al. (2002). fMRI Evidence for Dual Routes to the Mental Lexicon in Visual Word Recognition. Journal of Cognitive Neuroscience, 14, 11-23. https://doi.org/10.1162/089892902317205285

Fisch, B. J. (1991). Spehlmann's EEG Primer. Amsterdam: Elsevier Science Limited.

Fox, P. T., \& Raichle, M. E. (1986). Focal Physiological Uncoupling of Cerebral Blood Flow and Oxidative Metabolism during Somatosensory Stimulation in Human Subjects. Proceedings of the National Academy of Sciences, 83, 1140-1144. https://doi.org/10.1073/pnas.83.4.1140

Gervain, J. et al. (2011). Near-Infrared Spectroscopy: A Report from the McDonnell Infant Methodology Consortium. Developmental Cognitive Neuroscience, 1, 22-46. https://doi.org/10.1016/j.dcn.2010.07.004

Horovitz, S. G., \& Gore, J. C. (2004). Simultaneous Event-Related Potential and Near-Infrared Spectroscopic Studies of Semantic Processing. Human Brain Mapping, 22, 110-115. https://doi.org/10.1002/hbm.20018

Hoshi, Y., \& Michael, F. (2005). Functional Near-Infrared Spectroscopy: Potential and Limitations in Neuroimaging Studies. International Review of Neurobiology, 66, 237-266. https://doi.org/10.1016/S0074-7742(05)66008-4

Hull, R., \& Vaid, J. (2006). Laterality and Language Experience. Laterality, 11, 436-464. https://doi.org/10.1080/13576500600691162

Ibrahim, R. (2009). The Cognitive Basis of Diglossia in Arabic: Evidence from a Repetition Priming Study within and between Languages. Psychology Research and Behavior Management, 2, 93. https://doi.org/10.2147/PRBM.S5138

Ibrahim, R. et al. (2002). The Characteristics of Arabic Orthography Slow Its Processing. Neuropsychology, 16, 322. https://doi.org/10.1037/0894-4105.16.3.322

Ibrahim, R., \& Aharon-Peretz, J. (2005). Is Literary Arabic a Second Language for Native Arab Speakers? Evidence from Semantic Priming Study. Journal of Psycholinguistic Research, 34, 51-70. https://doi.org/10.1007/s10936-005-3631-8

Ibrahim, R., \& Aharon-Peretz, J. (2005). Is Literary Arabic a Second Language for Native Arab Speakers? Evidence from Semantic Priming Study. Journal of Psycholinguistic Research, 34, 51-70. https://doi.org/10.1007/s10936-005-3631-8

Ibrahim, R., \& Eviatar, Z. (2009). Language Status and Hemispheric Involvement in Reading: Evidence from Trilingual Arabic Speakers Tested in Arabic, Hebrew, and English. Neuropsychology, 23, 240.

Ibrahim, R., \& Eviatar, Z. (2012). The Contribution of the Two Hemispheres to Lexical Decision in Different Languages. Behavioral and Brain Functions, 8, 3. https://doi.org/10.1186/1744-9081-8-3

Jasinska, K. K., \& Petitto, L.-A. (2013). How Age of Bilingual Exposure Can Change the Neural Systems for Language in the Developing Brain: A Functional near Infrared Spectroscopy Investigation of Syntactic Processing in Monolingual and Bilingual Children. Developmental Cognitive Neuroscience, 6, 87-101. https://doi.org/10.1016/j.dcn.2013.06.005

Jasińska, K., \& Petitto, L. (2014). Development of Neural Systems for Reading in the Monolingual and Bilingual Brain: New Insights from Functional near Infrared Spectros- 
copy Neuroimaging. Developmental Neuropsychology, 39, 421-439. https://doi.org/10.1080/87565641.2014.939180

Joubert, S. et al. (2004). Neural Correlates of Lexical and Sublexical Processes in Reading. Brain and Language, 89, 9-20. https://doi.org/10.1016/S0093-934X(03)00403-6

Kahlaoui, K. et al. (2007). Semantic Processing of Words in the Aging Brain: A Near-Infrared Spectroscopy (NIRS) Study. Brain and Language, 1, 144-145. https://doi.org/10.1016/j.bandl.2007.07.087

Kashti, O. (2013). Israeli Student Achievement Does Not Leave much Room for Optimism. Ha'aretz, December 3.

Keatley, C. W. et al. (1994). Asymmetrical Cross-Language Priming Effects. Memory \& Cognition, 22, 70-84. https://doi.org/10.3758/BF03202763

Khamis-Dakwar, R., \& Froud, K. (2007). Lexical Processing in Two Language Varieties. Perspectives on Arabic Linguistics. The Annual Symposium on Arabic Linguistics, Vol. 20, Kalamazoo, 112-141.

Khateb, A., \& Ibrahim, R. (2020). About the Neural Basis of Arabic Diglossia: Behavioral and Event-Related Potential Analysis of Word Processing in Spoken and Literary Arabic. In Handbook of Literacy in Diglossia and Dialectal Contexts: Psycholinguistic and Educational Perspectives (201-214). Berlin: Springer.

Kim, K. H. et al. (1997). Distinct Cortical Areas Associated with Native and Second Languages. Nature, 388, 171-174. https://doi.org/10.1038/40623

Kronbichler, M. et al. (2004). The Visual Word Form Area and the Frequency with Which Words Are Encountered: Evidence from a Parametric fMRI Study. Neuroimage, 21, 946-953. https://doi.org/10.1016/j.neuroimage.2003.10.021

Levin, I. et al. (2008). Early Literacy in Arabic: An Intervention Study among Israeli Palestinian Kindergartners. Applied Psycholinguistics, 29, 413-436.

https://doi.org/10.1017/S0142716408080193

Ludyga, S. et al. (2019). A Combined EEG-fNIRS Study Investigating Mechanisms Underlying the Association between Aerobic Fitness and Inhibitory Control in Young Adults. Neuroscience, 419, 23-33. https://doi.org/10.1016/j.neuroscience.2019.08.045

Mechelli, A. et al. (2003). Neuroimaging Studies of Word and Pseudoword Reading: Consistencies, Inconsistencies, and Limitations. Journal of Cognitive Neuroscience, 15, 260-271. https://doi.org/10.1162/089892903321208196

Miller, D. et al. (2018). Bilingual Cognition and Language: The State of the Science across Its Subfields. Amsterdam: John Benjamins Publishing Company.

Minagawa-Kawai, Y. et al. (2008). Optical Imaging of Infants' Neurocognitive Development: Recent Advances and Perspectives. Developmental Neurobiology, 68, 712-728. https://doi.org/10.1002/dneu.20618

Nevat, M. et al. (2014). When First Language Is Not First: An Functional Magnetic Resonance Imaging Investigation of the Neural Basis of Diglossia in Arabic. European Journal of Neuroscience, 40, 3387-3395. https://doi.org/10.1111/ejn.12673

Oi, M. et al. (2010). Semantic Judgment of Chinese-Japanese Bilinguals: A Near-Infrared Spectroscopy Study. Neuroreport, 21, 127-131. https://doi.org/10.1097/WNR.0b013e328334f235

Perani, D., \& Abutalebi, J. (2005). The Neural Basis of First and Second Language Processing. Current Opinion in Neurobiology, 15, 202-206.

https://doi.org/10.1016/j.conb.2005.03.007

Plichta, M. M. et al. (2011). Auditory Cortex Activation Is Modulated by Emotion: A Functional Near-Infrared Spectroscopy (fNIRS) Study. Neuroimage, 55, 1200-1207. 
https://doi.org/10.1016/j.neuroimage.2011.01.011

Quaresima, V. et al. (2002). Lateral Frontal Cortex Oxygenation Changes during Translation and Language Switching Revealed by Non-Invasive Near-Infrared Multi-Point Measurements. Brain Research Bulletin, 59, 235-243. https://doi.org/10.1016/S0361-9230(02)00871-7

Quaresima, V. et al. (2012). A Brief Review on the Use of Functional Near-Infrared Spectroscopy (fNIRS) for Language Imaging Studies in Human Newborns and Adults. Brain and Language, 121, 79-89. https://doi.org/10.1016/j.bandl.2011.03.009

Safi, D. et al. (2012). Functional Near-Infrared Spectroscopy for the Assessment of Overt Reading. Brain and Behavior, 2, 825-837. https://doi.org/10.1002/brb3.100

Saiegh-Haddad, E. (2003). Linguistic Distance and Initial Reading Acquisition: The Case of Arabic Diglossia. Applied Psycholinguistics, 24, 431-451. https://doi.org/10.1017/S0142716403000225

Saiegh-Haddad, E. (2004). The Impact of Phonemic and Lexical Distance on the Phonological Analysis of Words and Pseudowords in a Diglossic Context. Applied Psycholinguistics, 25, 495-512. https://doi.org/10.1017/S0142716404001249

Saiegh-Haddad, E. (2005). Correlates of Reading Fluency in Arabic: Diglossic and Orthographic Factors. Reading and Writing, 18, 559-582. https://doi.org/10.1007/s11145-005-3180-4

Saiegh-Haddad, E. (2007). Linguistic Constraints on Children's Ability to Isolate Phonemes in Arabic. Applied Psycholinguistics, 28, 607-625. https://doi.org/10.1017/S0142716407070336

Saiegh-Haddad, E. (2018). MAWRID: A Model of Arabic Word Reading in Development. Journal of Learning Disabilities, 51, 454-462. https://doi.org/10.1177/0022219417720460

Saiegh-Haddad, E. (2020). A Psycholinguistic-Developmental Perspective on the Role of Diglossia in Reading: Issues, Methods, and Findings in Arabic as a Testcase. In Handbook of Literacy in Diglossia and Dialectal Contexts: Psycholinguistic and Educational Perspectives (76-98). Berlin: Springer.

Saiegh-Haddad, E. et al. (2011). The Linguistic Affiliation Constraint and Phoneme Recognition in Diglossic Arabic. Journal of Child Language, 38, 297-315. https://doi.org/10.1017/S0305000909990365

Saiegh-Haddad, E., \& Geva, E. (2008). Morphological Awareness, Phonological Awareness, and Reading in English-Arabic Bilingual Children. Reading and Writing, 21, 481-504. https://doi.org/10.1007/s11145-007-9074-X

Saiegh-Haddad, E., \& Joshi, R. M. (2014). Handbook of Arabic Literacy: Insights and Perspectives. Berlin: Springer Science \& Business Media. https://doi.org/10.1007/978-94-017-8545-7

Saiegh-Haddad, E., \& Schiff, R. (2016). The Impact of Diglossia on Voweled and Unvoweled Word Reading in Arabic: A Developmental Study from Childhood to Adolescence. Scientific Studies of Reading, 20, 311-324. https://doi.org/10.1080/10888438.2016.1180526

Saiegh-Haddad, E., \& Spolsky, B. (2014). Acquiring Literacy in a Diglossic Context: Problems and Prospects. In Handbook of Arabic Literacy (pp. 225-240). Dordrecht: Springer. https://doi.org/10.1007/978-94-017-8545-7_10

Saiegh-Haddad, E., \& Taha, H. (2017). The Role of Morphological and Phonological Awareness in the Early Development of Word Spelling and Reading in Typically Developing and Disabled Arabic Readers. Dyslexia, 23, 345-371. 
https://doi.org/10.1002/dys.1572

Schiff, R., \& Saiegh-Haddad, E. (2018). Development and Relationships between Phonological Awareness, Morphological Awareness and Word Reading in Spoken and Standard Arabic. Frontiers in Psychology, 9, 356. https://doi.org/10.3389/fpsyg.2018.00356

Seghier, M. L. et al. (2004). Variability of fMRI Activation during a Phonological and Semantic Language Task in Healthy Subjects. Human Brain Mapping, 23, 140-155. https://doi.org/10.1002/hbm.20053

Sela, I. et al. (2012). A Working Memory Deficit among Dyslexic Readers with No Phonological Impairment as Measured Using the N-Back Task: An fNIR Study. PLoS ONE, 7, e46527. https://doi.org/10.1371/journal.pone.0046527

Strangman, G. et al. (2002). A Quantitative Comparison of Simultaneous Bold fMRI and NIRS Recordings during Functional Brain Activation. Neuroimage, 17, 719-731. https://doi.org/10.1006/nimg.2002.1227

Sugiura, L. et al. (2011). Sound to Language: Different Cortical Processing for First and Second Languages in Elementary School Children as Revealed by a Large-Scale Study Using fNIRS. Cerebral Cortex, 21, 2374-2393. https://doi.org/10.1093/cercor/bhr023

Taha, H. et al. (2013). How Does Arabic Orthographic Connectivity Modulate Brain Activity during Visual Word Recognition: An ERP Study. Brain Topography, 26, 292-302. https://doi.org/10.1007/s10548-012-0241-2

Taha, H., \& Saiegh-Haddad, E. (2017). Morphology and Spelling in Arabic: Development and Interface. Journal of Psycholinguistic Research, 46, 27-38.

https://doi.org/10.1007/s10936-016-9425-3

Telkemeyer, S. et al. (2009). Sensitivity of Newborn Auditory Cortex to the Temporal Structure of Sounds. Journal of Neuroscience, 29, 14726-14733. https://doi.org/10.1523/JNEUROSCI.1246-09.2009

Vanderwert, R. E., \& Nelson, C. A. (2014). The Use of Near-Infrared Spectroscopy in the Study of Typical and Atypical Development. Neuroimage, 85, 264-271. https://doi.org/10.1016/j.neuroimage.2013.10.009

Vannasing, P. et al. (2016). Distinct Hemispheric Specializations for Native and Non-Native Languages in One-Day-Old Newborns Identified by fNIRS. Neuropsychologia, 84, 63-69. https://doi.org/10.1016/j.neuropsychologia.2016.01.038

Zughoul, M. R. (1980). Diglossia in Arabic: Investigating Solutions. Anthropological Linguistics, 22, 201-217. 